\title{
Endoscopic ultrasound-guided injection of coils for the treatment of refractory post-ERCP bleeding
}

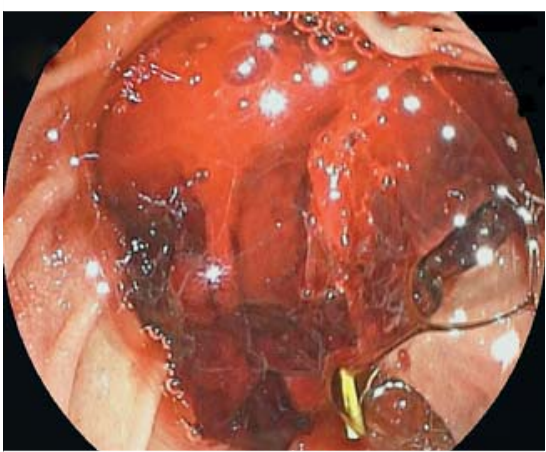

- Fig. 1 The papilla showed persistent active bleeding.

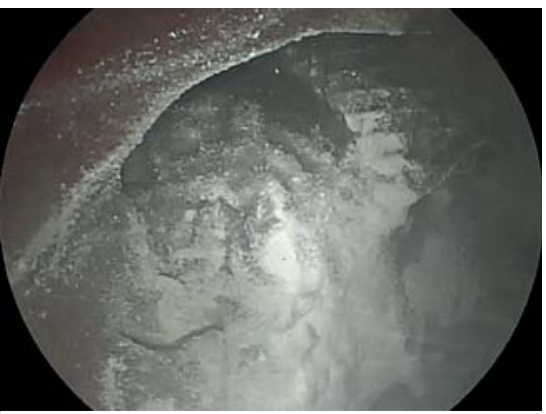

Fig. 2 Hemostatic powder was used for the first rebleeding.

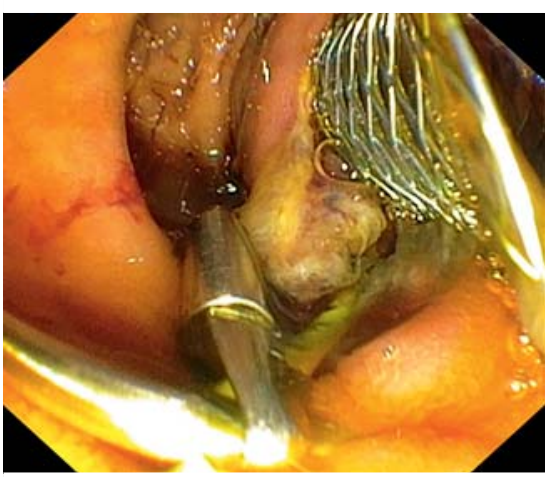

- Fig. 3 Duodenoscopy was performed immediately after embolization, and the absence of bleeding was confirmed.

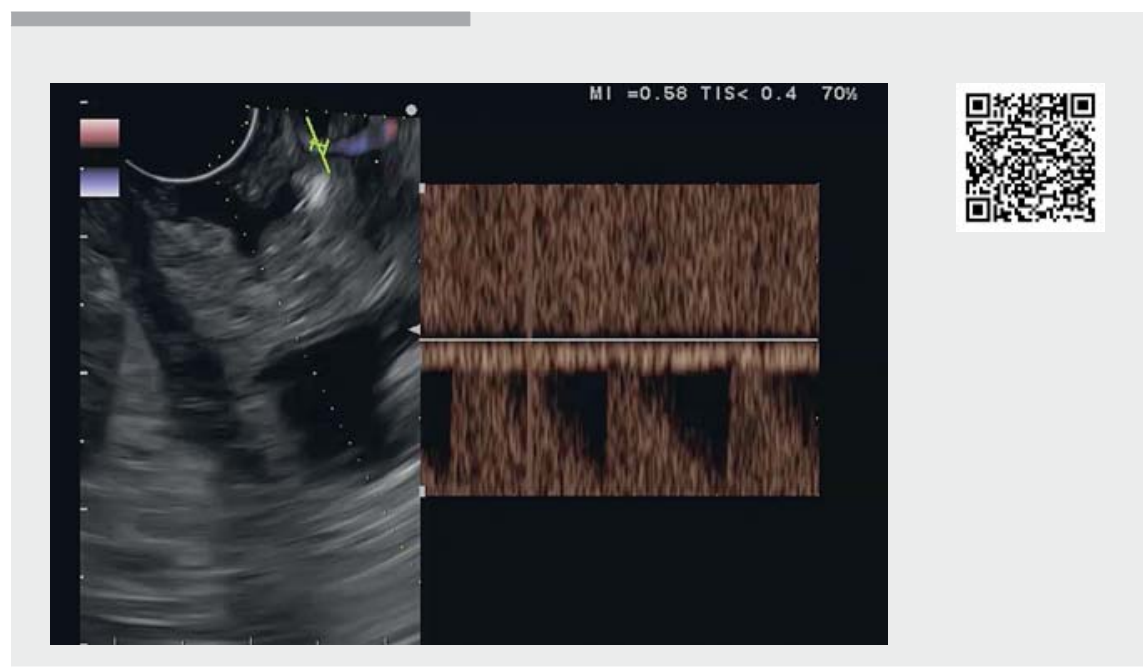

Video 1 Endoscopic ultrasound identified an arterial vessel in the duodenal wall at the level of the papilla. Endoscopic ultrasound-guided embolization was performed with a 0.018 " coil through a 22-gauge needle. The absence of blood flow in the blood vessel after therapy was confirmed by color Doppler imaging.

An 82-year-old woman was referred for endoscopic retrograde cholangiopancreatography (ERCP) for choledocholithiasis. After cannulation of the pancreatic duct, transpancreatic sphincterotomy and placement of a 5-fr stent in the pancreas were performed.

A fully covered self-expandable metal stent was placed because of persistent post-biliary sphincterotomy bleeding. The next day, the patient showed melena, hematemesis, and decreased hemoglobin levels. A gastroscopy was performed and active oozing bleeding from the papilla was evident. Injection therapy with epinephrine and hemoclips was performed. A few hours later, a new episode of hematochezia occurred. Repeat endoscopy showed persistent active bleeding from the papilla ( $\triangleright$ Fig. 1 ). Hemostatic powder (Hemospray; Cook Medical, Winston Salem, North Carolina, USA) was

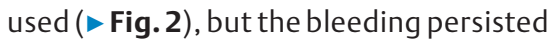
24 hours later.

Endoscopic ultrasound (EUS) was performed. A curvilinear array echoendo- scope (GF-UCT180; Olympus, Tokyo, Japan) that allowed color Doppler imaging was advanced to the second portion of the duodenum to visualize the peripapillary vascular anatomy. An arterial vessel was identified in the duodenal wall at the level of the papilla. EUS-guided embolization was performed with a 0.018 " coil (Tornado; Cook Medical, Inc., Bloomington, Indiana, USA) through a 22-gauge needle. Color Doppler imaging confirmed the absence of blood flow after therapy ( Video 1). Duodenoscopy was performed immediately after embolization, and the absence of bleeding was confirmed ( $>$ Fig. 3 ).

The efficacy of EUS-guided treatments of nonvariceal upper gastrointestinal bleeding has been reported only in the form of small case series and case reports [1]. Fockens et al. [2] first reported on the usefulness of EUS in the diagnosis and treatment of small abnormal vessels in patients with Dieulafoy's lesions. Currently, series have been described with success rates of $88 \%-100 \%$ in the treat- 
ment of gastrointestinal stromal tumors, Dieulafoy lesions, duodenal ulcers, pancreatic pseudoaneurysms, ulcers related to esophageal cancer, and after Roux-in$Y$ gastric bypass [3 - 5]. EUS-guided injection of coils for the treatment of refractory post-ERCP bleeding has not been reported in the literature.

In conclusion, EUS-guided injection of coils is a safe and effective alternative for the treatment of refractory postERCP bleeding if other conventional techniques have failed.

\section{Endoscopy_UCTN_Code_CPL_1AK_2AC}

\section{Competing interests}

The authors declare that they have no conflict of interest.

The authors

Edson Guzmán-Calderón ${ }^{1,2}$, Francisco Ruiz ${ }^{3}$, Juan Antonio Casellas ${ }^{3}$, Juan MartinezSempere $^{3}$, Lucía Medina-Prado ${ }^{3}$, Jose R. Aparicio $^{3}$

1 Gastroenterology Unit of Hospital Nacional Edgardo Rebagliati Martins, Lima, Peru

2 Universidad Peruana de Ciencias Aplicadas (UPC), Lima, Peru

3 Gastroenterology Unit oh Hospital General Universitario de Alicante, Alicante, Spain
Corresponding author

\section{Edson Guzmán-Calderon, MD}

Digestive Unit, Hospital Nacional Edgardo Rebagliati Martins, Domingo Cueto s/n Lima, Lima 13, Prol Manco II, 115 Condominio Villa Marina, Block A, 1101 San Miguel, Peru edson_guzman@hotmail.com

\section{References}

[1] Fabbri C, Luigiano C, Lisotti A et al. Endoscopic ultrasound-guided treatments: Are we getting evidence based - a systematic review. World J Gastroenterol 2014; 20: 8424-8448

[2] Fockens P, Meenan J, van Dullemen HM et al. Dieulafoy's disease: endosonographic detection and endosonography-guided treatment. Gastrointest Endosc 1996; 44: 437442

[3] Oleas R, Robles-Medranda C. Insights into the role of endoscopic ultrasound-guided vascular therapy. Ther Adv Gastrointest Endosc 2019; 12: 2631774519878282

[4] Levy M], Wong Kee Song LM, Farnell MB et al. Endoscopic ultrasound (EUS)-guided angiotherapy of refractory gastrointestinal bleeding. Am J Gastroenterol 2008; 103: 352-359

[5] Law R, Fujii-Lau L, Wong Kee Song LM et al. Efficacy of endoscopic ultrasound-guided hemostatic interventions for resistant nonvariceal bleeding. Clin Gastroenterol Hepatol 2015; 13: 808.e1-812.e1
Bibliography

DOI https://doi.org/10.1055/a-1103-1806

Published online: 12.2 .2020

Endoscopy 2020; 52: 702-703

(c) Georg Thieme Verlag KG

Stuttgart · New York

ISSN 0013-726X

\section{ENDOSCOPY E-VIDEOS}

https://eref.thieme.de/e-videos

口回 Endoscopy E-Videos is a free access online section, reporting 回: on interesting cases and new

techniques in gastroenterological endoscopy. All papers include a high quality video and all contributions are freely accessible online.

This section has its own submission website at https://mc.manuscriptcentral.com/e-videos 